\title{
ACTIVITY OF MERCURY IN ITS AMALGAMS AT MOLTEN STAGE
}

\author{
S. K. Chakrabarti*, B. K. Jha* and I. S. Jha* \\ *Department of Physics, M. M. A. M. Campus, Tribhuvan University, Biratnagar, Nepal.
}

\begin{abstract}
In the present work we have considered two molten amalgams e.g. sodium amalgam and potassium amalgam. Efforts are made to compute the activity of mercury therein by applying Flory's model. This statistical mechanical model is based on the size factor of the ingredients of a binary liquid alloy. In case of each of the amalgams we have started with the expression for the free energy of mixing $\left(G_{M}\right)$ according to this model. After knowing the ratio of the atomic volumes of the constituent species of an amalgam the prime task becomes the determination of the interchange energy $(\omega)$ between them. For this purpose the experimental values of $\mathrm{G}_{\mathrm{M}}$ for different concentrations of the ingredients of the amalgam are collected. From these known values $\omega$ has been computed by using the expression for $G_{M}$. A suitable value of $\omega$ is chosen from the set of values so obtained. Putting this value of $\omega$ the free energy of mixing is calculated for several concentrations and then compared with its observed values. Accordingly, a modified value of $\omega$ has been considered and the calculations are repeated. In this way by the method of successive approximations we have ascertained the value of the interchange energy. Thereafter, with the help of standard thermodynamic relation activity has been computed. The results explain the observed anomaly of the activity of mercury in the present molten amalgams.
\end{abstract}

Keywords: Binary liquid alloys; Flory’s model; Amalgams; Activity of mercury.

\section{INTRODUCTION}

Mercury, the only liquid metal at normal temperature, is usually reluctant to mix up homogeneously with other materials due to high cohesive force between its molecules. However, it dissolves many metals at their molten stage in order to form amalgams of them. The thermodynamic properties of these molten amalgams deviate considerably from the ideal values. The alloying behaviour of liquid amalgams can be studied by the help of electronic theory of mixing and also by the statistical mechanical theory of mixing. According to the first theory a liquid amalgam is assumed to consist of a system of ions and electrons. The problem, usually, in this approach is tackled through pseudopotential theory and hard sphere model. The approach cannot be used to obtain information regarding the concentration fluctuations in the long wave-length limit $\left[\mathrm{S}_{c c}(0)\right]$, an important thermodynamic function which determines the stability of alloys. The other theory can be successfully used to obtain the analytical expressions for various thermodynamic functions that are not possible otherwise.

As regards mixing of two metals it is widely known that most metals dissolve in one another readily once they are in liquid phase but the same is not true for the solid alloys. The solubility of a homogeneous solid phase is governed predominantly by the size factor, electrochemical effect and electron concentration. Experiences show that these factors cannot be used effectively to explain the alloying behaviour of liquid alloys to a great deal. Thus liquid alloys generate manifold interests for the experimentalists ${ }^{1-3}$ as well as theoreticians $^{4-8}$.

In the present work the deviation from the ideal values of the activity of mercury has been considered for the purpose of study in case of two molten amalgams e.g. Hg-Na and Hg-K. Flory's model is used to explain such anomaly. The model is based on the statistical mechanical theory of mixing in which the size factor of the constituent species of the alloy is considered.

Working expressions are summarised in Section 2. Section 3 deals with the results. A brief conclusion is provided in Section 4 .

\section{FORMULATION}

Activity is one of the fortunate thermodynamic functions which are obtained directly from experiment. The activity (a) of an element in a binary liquid alloy is given by

$$
\mathrm{K}_{\mathrm{B}} \mathrm{T} \ln \mathrm{a}=-\mathrm{zFE},
$$

where ' $z$ ' is the valency of carrier ions of the element, $F$ the Faraday's constant, $\mathrm{K}_{\mathrm{B}}$ the Boltzmann constant, $\mathrm{T}$ the absolute 
temperature and $\mathrm{E}$ the electromotive force which is observed directly from the experiment.

In order to obtain the expression for 'a' let us recall the standard thermodynamic relation :

$R T \ln a=G_{M}+(1-c) \frac{\partial G_{M}}{\partial c}$,

where $R$ is the universal gas constant, $G_{M}$ the free energy of mixing and ' $\mathrm{C}$ ' the concentration of the element within the alloy.

Flory's expression for the free energy of mixing of a binary mixture consisting of Nc mole of species A and N(1-c) mole of species $\mathrm{B}$ is given by ${ }^{9}$

$\mathrm{G}_{\mathrm{M}}=\mathrm{RT}[\mathrm{cln} \mathrm{c}+(1-\mathrm{c}) \ln (\mathrm{l}-\mathrm{c})+\mathrm{cln}(1-\mathrm{v})-\ln (1-\mathrm{vc})]+$

$\omega \mathrm{C}$

where $v=1-$

$\mathrm{V}_{\mathrm{A}}$ and $\mathrm{V}_{\mathrm{B}}$ being the atomic volumes of species $\mathrm{A}$ and $\mathrm{B}$ respectively and $\omega$ the interchange energy.

Differentiating equation (2) with respect to 'c',

$\frac{\partial \mathrm{G}_{\mathrm{M}}}{\partial \mathrm{c}}=\mathrm{RT}\left[\ln \mathrm{c}-\ln (1-\mathrm{c})+\ln (1-\mathrm{v})+\frac{\mathrm{v}}{1-\mathrm{vc}}\right]+\omega\left[\frac{1-2 \mathrm{c}}{1-\mathrm{vc}}+\frac{\mathrm{v}(1-\mathrm{c}) \mathrm{c}}{(1-\mathrm{vc})^{2}}\right]$

Using equations (2) and (4) in equation (1) we get

\section{RESULTS AND DISCUSSION}

\subsection{Sodium amalgam at molten stage}

For the purpose of equation (3) considering $\mathrm{A} \equiv \mathrm{Hg}$ and $\mathrm{B} \equiv$ Na we have $\mathrm{V}_{\mathrm{B}} / \mathrm{V}_{\mathrm{A}}=1.698 \mathrm{at}^{10} 673 \mathrm{~K}$. After finding $v$ the value of interchange energy has been determined on using equation (2) from the observed data ${ }^{1}$ of $G_{M}$ in the concentration range of mercury from 0.1 to 0.9 by the method of successive approximations. The value of $\omega / \mathrm{RT}$ used in the present work is -7.5. Equation (5) has been used to compute ln $\mathrm{a}_{\mathrm{Hg}}$ at $673 \mathrm{~K}$. and then tabulate in Table 1.

Table 1: Activity of Hg in Hg-Na liquid alloys at $673 \mathrm{~K}$.

*Hultgren et al, 1973

$\ln \mathrm{a}_{\mathrm{Hg}}$ is plotted against $\mathrm{c}_{\mathrm{Hg}}$ in Figure 1 along with its experimental values ${ }^{1}$ at $673 \mathrm{~K}$. The computed and observed values are in well agreement. It is observed that the activity of $\mathrm{Hg}$ in the sodium amalgam remains quite small for most of the concentrations i.e. $\mathrm{c}_{\mathrm{Hg}} \quad 0.6$ and then it rises very fast in the region $\mathrm{c}_{\mathrm{Hg}}>0.7$. Slight disagreement between the theoretical and experimental values of $\ln \mathrm{a}_{\mathrm{Hg}}$ is noticed for concentrations of $\mathrm{Hg}$ in between $20 \%$ and $50 \%$. This may be due to the formation of complexes within the alloy ${ }^{1}$.

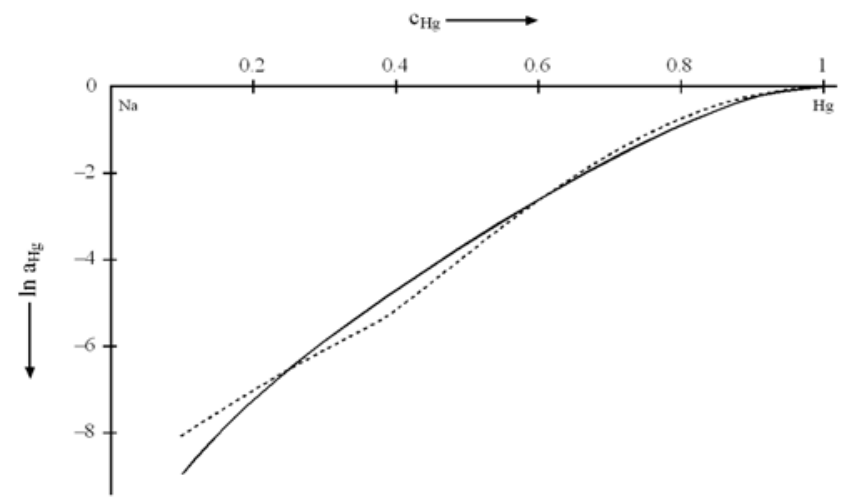

Figure 1. Activity (ln $\mathrm{a}_{-\mathrm{Hg}}$ ) of mercury in the molten sodium amalgam at $673 \mathrm{~K}$. for different concentrations of $\mathrm{Hg}$. The full curve represents the theoretical values. The dotted curve shows the experimental values due to Hultgren et al (1973).

\subsection{Potassium amalgam at molten stage}

Here, considering AHg and BK we have $\mathrm{V}_{\mathrm{B}} / \mathrm{V}_{\mathrm{A}}=3.3 \mathrm{at}^{10} 600 \mathrm{~K}$. Calculating $v$ the value of interchange energy is then determined from the observed data ${ }^{1}$ of $G_{M}$ in the concentration range of mercury from 0.1 to 0.9 . The value of $\omega / \mathrm{RT}$ has been found out to be -5.51 by the method of successive approximations. The computed values of $\ln \mathrm{a}_{\mathrm{Hg}}$ at $600 \mathrm{~K}$. are shown in Table 2.

Table 2: Activity of Hg in Hg-K liquid alloys at $600 \mathrm{~K}$.

\section{*Hultgren et al, 1973}

These computed values of $\ln \mathrm{a}_{\mathrm{Hg}}$ are plotted against the concentrations of mercury in Figure 2 along with the experimental values ${ }^{1}$ at $600 \mathrm{~K}$. The computed and observed values of activity are in considerable agreement. It is found that the activity of mercury in the potassium amalgam remains quite a small value for most of the concentrations i.e. $\mathrm{c}_{\mathrm{Hg}} \leq 0.7$ and then it rises sharply. There is slight disagreement between the theoretical and experimental values of $\ln \mathrm{a}_{\mathrm{Hg}}$ for concentrations of mercury below $60 \%$. This may be due to the formation of complexes within the alloy ${ }^{1}$. 


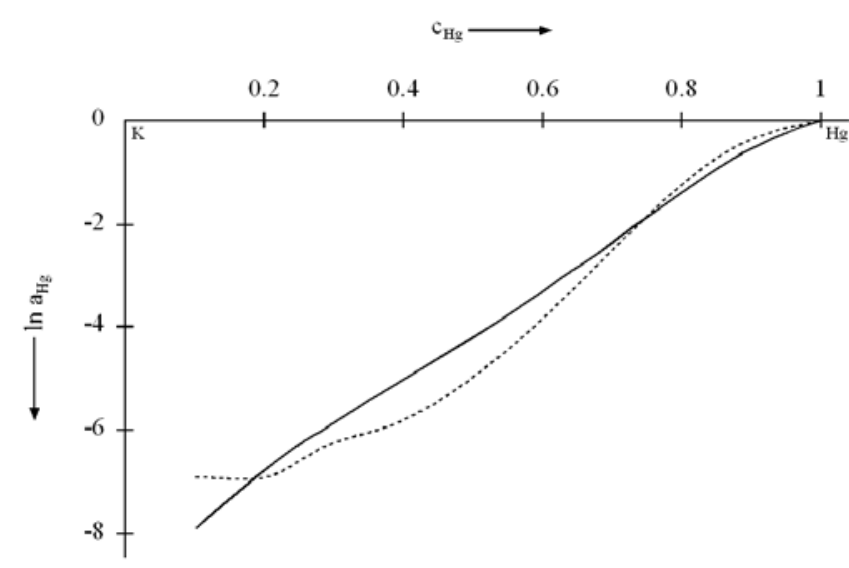

Figure 2. Activity ( $\ln \mathrm{a}_{-\mathrm{Hg}}$ ) of mercury in the molten potassium amalgam at $600 \mathrm{~K}$. for different concentrations of $\mathrm{Hg}$. The full curve represents the theoretical values. The dotted curve shows the experimental values due to Hultgren et al (1973).

\section{SUMMARY AND CONCLUSION}

Flory's model has been considered to study the concentration dependence of the activity of mercury in the Hg- $\mathrm{Na}$ and $\mathrm{Hg}$ $\mathrm{K}$ liquid alloys. Our theoretical investigation explains the deviation from the ideal values of the activity of $\mathrm{Hg}$ in these molten amalgams to a great extent. The nature of curves as found experimentally is well corroborated by our theoretical values for different concentrations.

\section{REFERENCES}

1 Hultgren, R., Desai, P.D., Hawkins, D.T., Gleiser, M. and Kelley, K.K. 1973. Selected values of the thermodynamic properties of binary alloys. A. S. M., Ohio.

2 Saboungi, M.L., Marr, J. and Blander, M. 1978. J. Chem. Phys. 68: 1375.

3 Harada, S., Takahashi, S., Takeda, S., Tamaki, S., Grey P. and Cusack, N.E. 1988. J. Phys. F18: 559.

4 Harrison, W.A. 1966. Pseudopotential in the theory of metals. Benjamin, New York.

5 Faber, T.E. 1972. Introduction to the theory of liquid metals. Cambridge Univ. Press, Cambridge.

6 Sommer, F. 1983. Bunsen-Ges. Phys. Chem. 87: 749.

7 Prasad, L.C. and Singh, R.N. 1990. Phys. Chem. Liq. 22: 1.

8 Chakrabarti, S.K., Jha, I.S., Kumar, A. and Singh, B.P. 2009. J. Chem. Pharm. Sc. 2: 6.

9 Flory, P.J. 1942. J. Chem. Phys. 10: 51.

10 Shimoji, M. 1977. Liquid metals. London Acad., London. 